\title{
Fabrication and performance evaluation of vertical farming structures
}

\author{
Shaheemath Suhara K K \\ Department of Soil and Water Conservation Engineering, Tamil Nadu Agricultural University, \\ Coimbatore - 641003 (Tamil Nadu), India \\ Priya G Nair \\ Department of Soil and Water Conservation Engineering, Kerala Agricultural University, \\ Thrissur - 680656 (Kerala,) India \\ "Corresponding author. Email: shaheemakaratt@gmail.com
}

\section{Article Info}

https://doi.org/10.31018/ jans.v13iSI.2777

Received: March 22, 2021

Revised: April 17, 2021

Accepted: May 8, 2021

\section{How to Cite}

Shaheemath Suhara K K and Nair, P.G. (2021). Fabrication and performance evaluation of vertical farming structures. Journal of Applied and Natural Science, 13 (SI), 55 - 62. https://doi.org/10.31018/jans.v13iSI.2777

\begin{abstract}
This study was undertaken to fabricate Vertical Farming Structures (VFS) suitable for homestead and evaluate the performance of fabricated vertical farming structures. The experiment was conducted in Kelappaji College of Agricultural Engineering and Technology (KCAET), Tavanur, in Malappuram district, Kerala. Two vertical farming structures DVFS 1 (Developed vertical farming structure 1) and DVFS 2 (Developed vertical farming structure 2) were designed and fabricated. The drip irrigation system was adopted to irrigate the plants to reduce the wastage of water. Amaranthus seedlings of variety 'Kannara local' was taken for the trial. Climatic parameters and biometric observations were analyzed to compare and evaluate the performances of vertical farming structures. Correlation analysis was done using IBM SPSS statistics 25 software. The analysis of trials revealed that DVFS 1 showed better performance in every aspect compared to DVFS 2 . The biometric observations like plant height and number of leaves were more in T1 at the right side and followed by T3 at the right side of DVFS 1. The plant characteristics are highly correlated with the light intensity. This was the reason for more growth was observed on the right side of DVFS 1 . The maximum yield was obtained from the DVFS $1(58 \%)$ than DVFS $2(42 \%)$. The study recommended that usage of the platform like structure with triangular cross-section was more advantageous than the structure with tiers one over the other with Poly Vinyl Chloride (PVC) splits.
\end{abstract}

Keywords: Biometric observation, Light intensity, Temperature, Urban farming

\section{INTRODUCTION}

Human population is increasing day by day. The United Nation (UN) reported that the human population will exceed 9 billion people by the year 2050 and thereby, it is necessary to produce 70 percentage more foods to ensure food security (United Nation, 2017). According to the United Nations' Food and Agriculture Organization (FAO), there was one acre of arable land per person on earth in the year 1961 and it shrinks to nearly half, about 0.56 acres by the year 2002 due to uncontrollable population growth and also due to urbanization (Despommier, 2010, Healy and Rosenberg, 2013, Thomaier et al., 2015, Al-Kodmany, 2018). By the year 2011, the United Nation concluded a global assessment of the planet's land resources, which reveals that a quarter of all cultivable land is highly degraded. If traditional farming practices continue as they are practiced today, an estimated $10^{7}$ square kilometers of additional land is to be required to grow sufficient food and thereby to meet demand of the ever increasing population (United Nation, 2017).

Apart from the problems imparted by the huge population on the environment, modern day agriculture is also a major contributor to a large range of environmental problems including agricultural runoff, degradation of the ecosystem, use of fossil fuels, food wastage, under capacity drainage infrastructure etc. (Al-Kodmany and Ali, 2013). As a best solution, nowadays horticulturalists and entrepreneurs are focusing on the practice of vertical farming, which is a component of urban agriculture, where cultivating food within skyscrapers or on vertically inclined surfaces, where crops would be cultivated and grown inside multi-storey buildings that will mimic the ecological system (Al-Kodmany, 2018a, Valley and Wittman, 2018). This farming practice encour- 
ages sustainable agricultural growth and enhances food security more than by conventional farming. It provides additional farmlands and ensures year-round crop production. Furthermore, vertical farming practices can save crops from floods, pests, weeds, extreme weather events, and drought as it is a farming practices in a controlled environment. Also, it can reduce deforestation and desertification caused by agricultural encroachment on natural biomass system (Omrani et al., 2017). In sight of all the above facts, this study was undertaken to fabricate Vertical Farming Structures (VFS) suitable for homestead and to evaluate the performance of the fabricated vertical farming structures.

\section{MATERIALS AND METHODS}

\section{Location of study}

The experiment was performed in KCAET, Tavanur, Kerala, located at the $10^{\circ} 51^{\prime} 13^{\prime \prime} \mathrm{N}$ and $75^{\circ} 59^{\prime} 9^{\prime \prime} \mathrm{E}$. The mean maximum and mean minimum temperature of the study area are $42.1^{\circ} \mathrm{C}$ and $22^{\circ} \mathrm{C}$, respectively and relative humidity about $80 \%$. The study area comes under a humid tropic climatic region so that area receives more extreme events during south-west monsoon.

\section{Fabrication of VFS}

Design and fabrication of two vertical farming structures named DVFS 1 (Developed Vertical Farming Structure 1) and DVFS 2 (Developed Vertical Farming Structure 2) were done suitable for homestead as well as urban farming.

The DVFS 1 is a platform like structure with a triangular cross section, consists three tiers (platforms) on each side. The structure has a dimension of $213 \mathrm{~cm} \times 163$ $\mathrm{cm} \times 213.3 \mathrm{~cm}$ (Fig. 1). It is a metallic structure, where frame and roof were made up of 0.5 " mild steel (MS) rods, 0.75 " MS tubes and 1" MS square tubes. Metallic seating (width $20.5 \mathrm{~cm}$ ) were provided by fixing MS flats of $3 / 4$ " $\times 1 / 8$ " for placing grow bags or garden pots. A total of 36 grow bags of size $15 \mathrm{~cm} \times 15 \mathrm{~cm}$ can be placed in the structure in such a way that 6 grow bags can be accommodated in each platform. The height of the structure excluding roof was fixed about $167 \mathrm{~cm}$ for easy harvesting of crops. The height of the first, second and third platform from top to bottom are $51 \mathrm{~cm}, 48 \mathrm{~cm}$ and $45 \mathrm{~cm}$, respectively, designed according to the height of the structure and width of platform. The roof has a quonset shape made up of MS rods of 1/2" diameter. The roof is supported by using MS rod of length $80 \mathrm{~cm}$ attached to the main structure at each corner. UV sheet of 200 microns of $230 \times 180 \mathrm{~cm}$ was used for covering the roof. Three rings (8 cm diameter) were provided on the roof to place the PVC pipe for irrigation.

The DVFS 2 had rectangular open shelves like structure with overall dimension of $155 \mathrm{~cm} \times 220 \mathrm{~cm} \mathrm{~m} \mathrm{x} 70$ $\mathrm{cm}$ (Fig. 2). This structure was also fabricated using MS square tubes (1 inch) and MS rods. Half splitted PVC pipes (6 inches diameter and $2.80 \mathrm{~mm}$ wall thickness) were used as a trough for filling growing media (Pradeepkumar et al., 2018). The structure has three tiers one over the other, which consisted 19 half splitted PVC pipes. The PVC splits were supported by semicircular rings ( $3 / 4$ " $\times 1 / 8$ " MS flat) welded with the frame. The structure had three sections; left, middle and right with

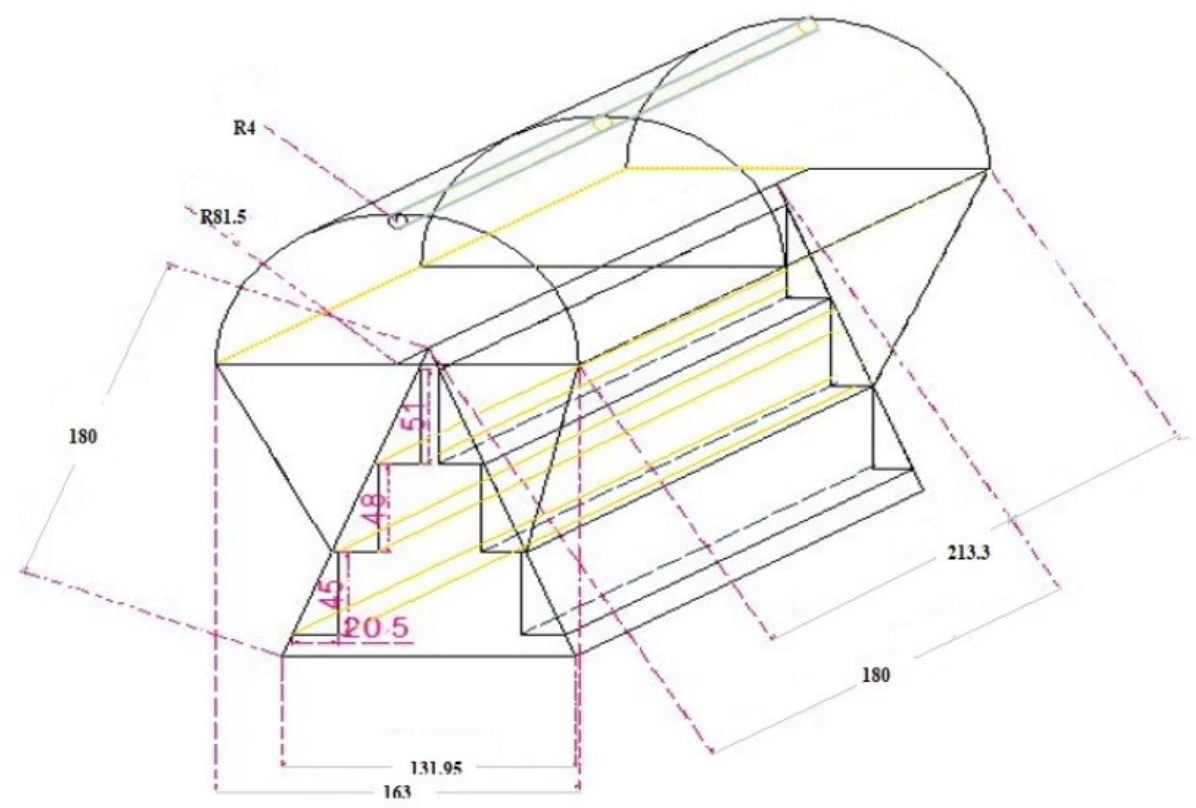

Fig. 1. Developed vertical farming structure 1 (DVFS 1). 


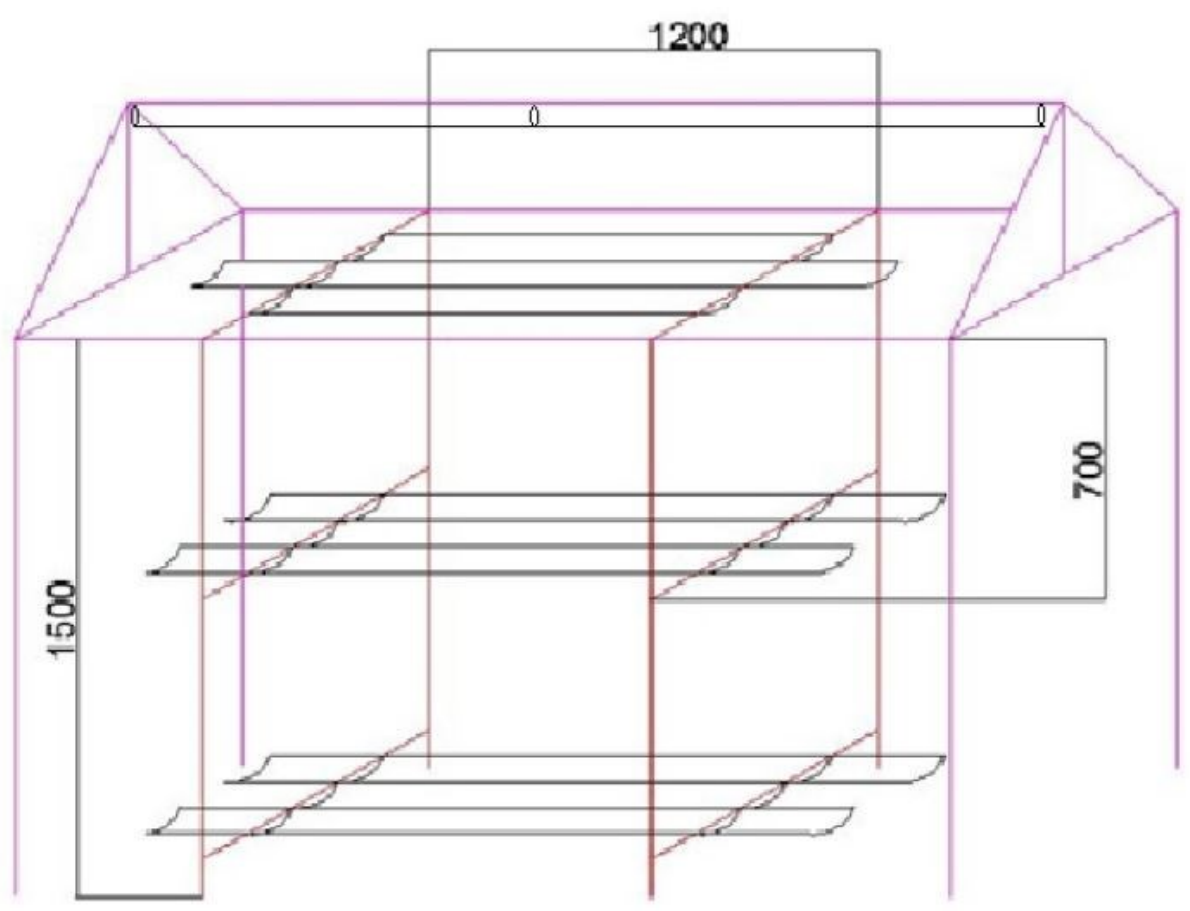

Fig. 2. Developed vertical farming structure 2 (DVFS 2).

length 50,120 and $50 \mathrm{~cm}$, respectively, so that each portion could assemble and dismantle easily using screws and bolts, making its transportation easier. The roof was provided as shown in the figure with the provision to place PVC pipes for irrigation as done in DVFS 1. The roof of the structure was covered with UV sheets of 200 micron thickness (Lamnatou and Chemisana, 2013).

\section{Setup for irrigation}

Irrigation was given daily by drip irrigation method, as it saves water and reduces losses (Postel et al., 2001, Vazquez et al., 2006, Wang et al., 2020). Water supplied to the system through gravity from the institution tank located $10 \mathrm{~m}$ above the structure.

\section{Field experiment}

Tier wise analysis of both structures was done to evaluate crop production performances, so that crops from each tiers were selected randomly from each side of both structures. Tiers are named as shown in Table 1 . Amaranthus of variety 'kannara local' was taken for the trial and seedling were placed in the grow bags as well as in the half split PVC pipes. The depth of rooting media in half split PVC pipes and grow bags was about 10 $\mathrm{cm}$. Two seedlings were placed in each grow-bags. The grow bags and PVC splits were mixed with coco peat and vermiculite at a ratio 3:1 (Rani et al., 2018). Climatic parameters such as temperature and light intensity were observed in morning, afternoon and evening during the growth stage of the crop (Marcelis et al.,
2006). Biometric observations such as plant height and number of leaves were made once a week. Harvesting was done after attaining maturity. The orientation of the structure was along the east-west direction according to institute direction and available space in the yard.

Table 1. Different tiers of the DVFS 1 AND DVFS 2 analyzed in this study.

\begin{tabular}{|c|c|}
\hline Tier & Position \\
\hline 1RT1 & top tier at the right side of DVFS 1 \\
\hline 1RT2 & middle tier at the right side of DVFS 1 \\
\hline 1RT3 & bottom tier at the right side of DVFS 1 \\
\hline 1LT1 & top tier at the left side of DVFS 1 \\
\hline 1LT2 & middle tier at the left side of DVFS 1 \\
\hline 1LT3 & bottom tier at the left side of DVFS 1 \\
\hline 2LT1 & top tier at left section of DVFS 2 \\
\hline 2LT2 & middle tier at left section of DVFS 2 \\
\hline 2LT3 & bottom tier at left section of DVFS 2 \\
\hline 2MT1 & top tier at the middle section of DVFS 2 \\
\hline 2MT2 & middle tier at the middle section of DVFS 2 \\
\hline 2MT3 & bottom tier at the middle section of DVFS 2 \\
\hline 2RT1 & top tier at the right section of DVFS 2 \\
\hline 2RT2 & middle tier at the right section of DVFS 2 \\
\hline 2RT3 & bottom tier at the right section of DVFS 2 \\
\hline
\end{tabular}




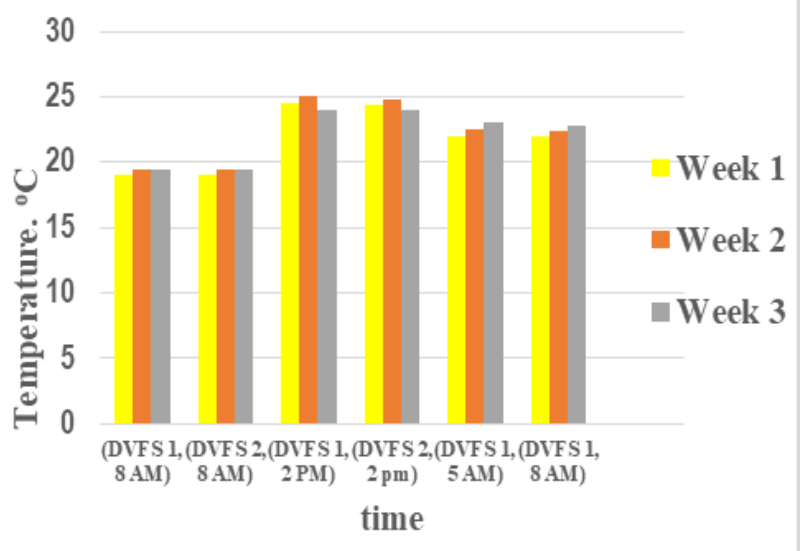

Fig. 3. Variations in air temperature in DVFS 1 and DVFS 2 at 8:00 am, 2:00 pm and 5:00 pm.

\section{Statistical analysis}

Correlation between climatic and biometric parameters was analyzed by correlation analysis (Franzese and Luliano, 2018) based on Pearson correlation coefficient at 0.01 significant level using SPSS Inc. 25 software.

\section{RESULTS AND DISCUSSION}

Climatic parameters such as air temperature and light intensity were observed in both structures at 8:00 am, 1:30 pm and 5:00 pm for a period of three weeks from December to January 2017.

\section{Air temperature}

The daily data were taken using a dry bulb thermometer and further calculated weekly average values from the daily data observed at 8:00 am, 2:00 pm and 5:00 pm and plotted as shown in Fig. 3. The minimum mean temperature measured at 8:00 am in DVFS 1 and

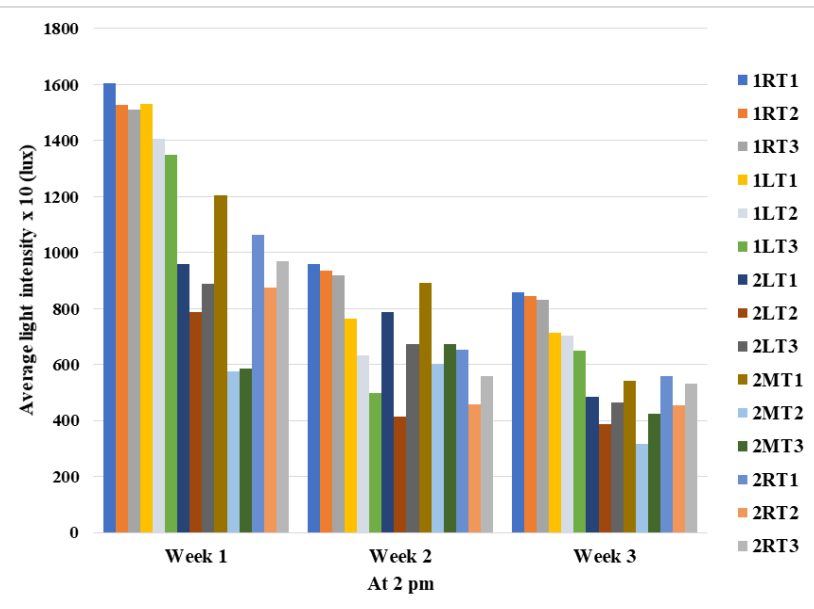

Fig. 5. Variations in light intensity in DVFS 1 and DVFS 2 at 2:00 pm.

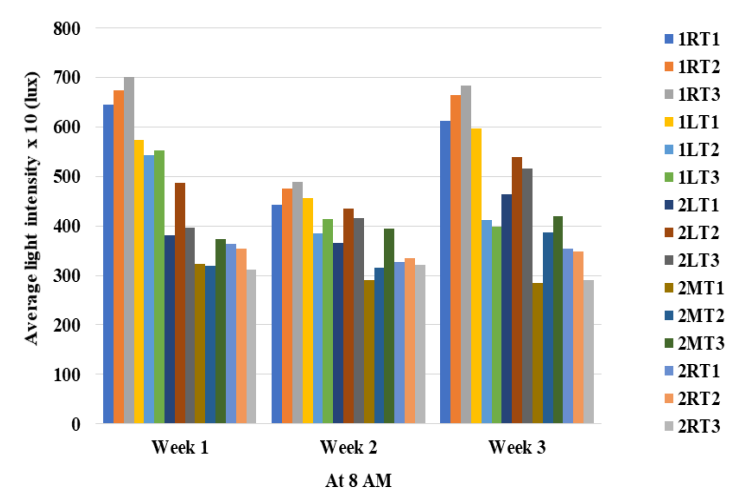

Fig. 4. Variations in light intensity in DVFS 1 and DVFS 2 at 8:00 am.

DVFS 2 were the same, about $19^{\circ} \mathrm{C}$. The maximum mean temperature observed in DVFS 1 was $19.5^{\circ} \mathrm{C}$ and in DVFS 2 was about $19.4^{\circ} \mathrm{C}$. Similarly, at 2:00 pm the maximum mean temperature noted in DVFS 1 was $25^{\circ} \mathrm{C}$ and in DVFS 2 was $24.8^{\circ} \mathrm{C}$. Minimum temperatures were $24^{\circ} \mathrm{C}$ in both the structures (Fig. 3). In the evening, the maximum temperature in DVFS 1 was about $23^{\circ} \mathrm{C}$ and in DVFS 2 , it was $22.8^{\circ} \mathrm{C}$. Minimum temperatures were the same for both structures i.e., 22 ${ }^{\circ} \mathrm{C}$. The slight increase in temperature observed in DVFS 1 compared to DVFS 2 is due to the structural difference. The former used metallic seating, whereas the other is with PVC splits as the metal has higher thermal conductivity than plastics. Michel et al. (2019) stated that the thermal conductivity of PVC is only $0.45 \%-0.6 \%$ of a steel tube.

Orientation of the structure (east-west) reflects the variation of the temperature among different tiers. The results are in agreement with Sethi (2009), where 3.5-5.5

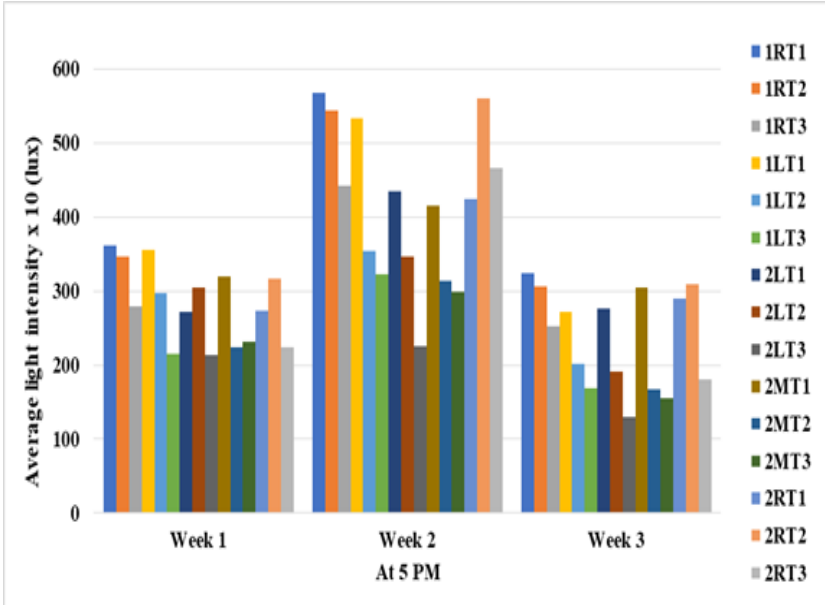

Fig. 6. Variations in light intensity in DVFS 1 and DVFS 2 at 5:00 pm. 
$C$ change in the air temperature was observed inside the greenhouse in east-west orientation.

\section{Light intensity}

The weekly average of light intensity was calculated for 8:00 am, 1:30 pm and 5:00 pm data, respectively, from the daily intensity data. Measurements were taken using lux meter in range B. Fig. 4 shows the variations in light intensity in DVFS 1 and DVFS 2 at 8:00 am. The maximum light intensity was obtained on tier 3 (T3) at the right side of DVFS 1. It was about 7010 lux. The minimum light intensity of 2850 lux was measured from tier 1 (T1) on the middle section of DVFS 2 . The receipt of solar radiation and reflected radiation obtained were maximum in tier 1 as it was close to the ground surface. Due to the orientation of the structure in the east-west direction, in morning hours, there was a possibility of receipt of more solar radiation in the left section of DVFS 2 as it was oriented towards east. Fig. 5 shows the variations in light intensity of DVFS 1 and

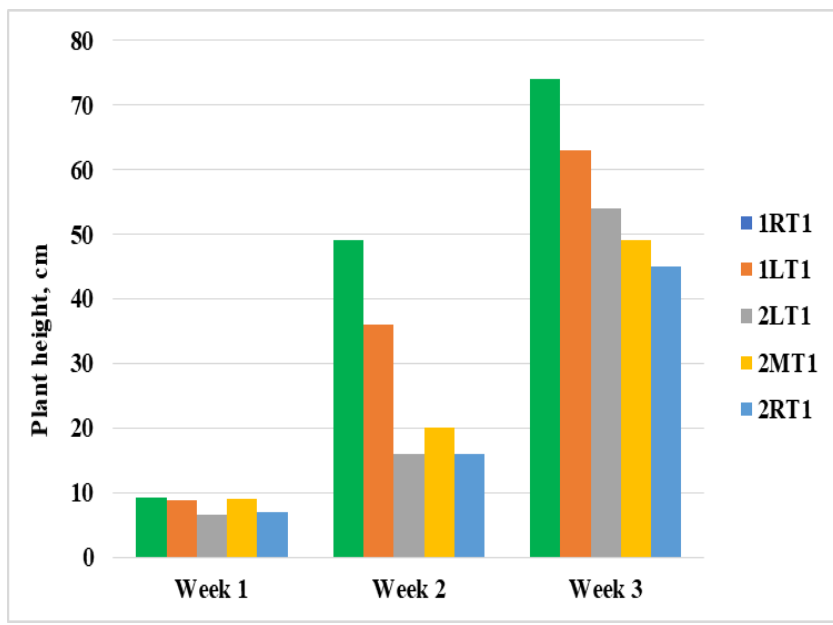

Fig. 7. Variation of plant height in T1 (tier 1) of DVFS 1 and DVFS 2.

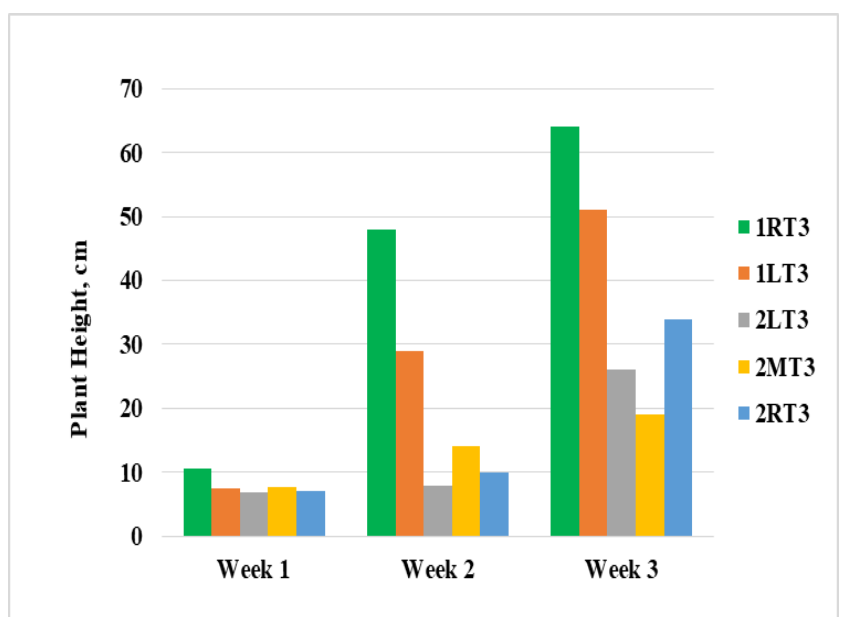

Fig. 9. Variation of plant height in T3 (tier 3) of DVFS 1 and DVFS 2.
DVFS 2 respectively at 2:00 pm. The maximum light intensity was observed on tier 1 (T1) at the right side of DVFS 1 (16050 lux). The minimum light intensity of 3180 lux was observed from tier 2 (T2) on the middle section of DVFS 2. Tier 1 was more close to the roof than other tiers, would receive directly transmitted light compared to other tiers. In DVFS 2, tier 2 (T2) is the middle tier shows less light intensity compared to tier1 (T1) and tier 3 (T3) as there was less availability of direct sunlight and reflected radiations. Fig. 6 showed the variations in light intensity in both structures at 5:00 pm. The maximum light intensity was obtained from tier 1 (T1) at the right side of DVFS 1 and it was about 5680 lux.

From these data, it was concluded that in the case of DVFS 1, always the maximum light intensity was observed on tier 1 on the right side of the structure due to the location of the structures and the availability of reflected and transmitted radiations. But in DVFS 2, maximum light intensity was observed in the left section

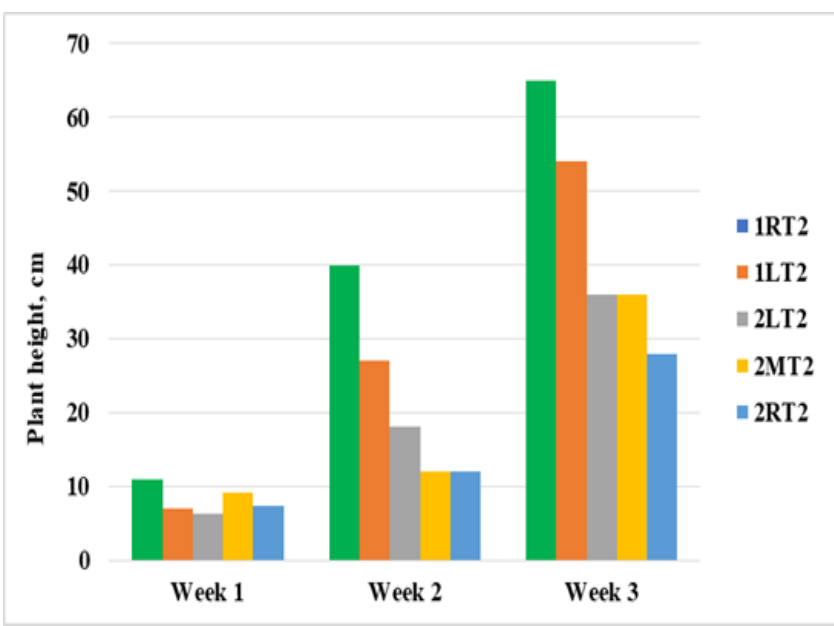

Fig. 8. Variation of plant height in T2 (tier 2) of DVFS 1 and DVFS 2.

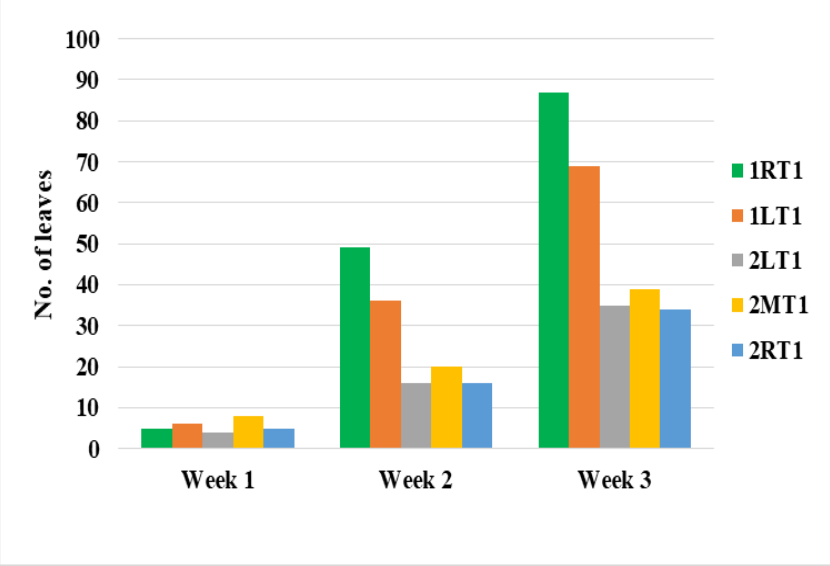

Fig. 10. Variation of number of leaves in $T 1$ (tier 1) of DVFS 1 and DVFS 2. 


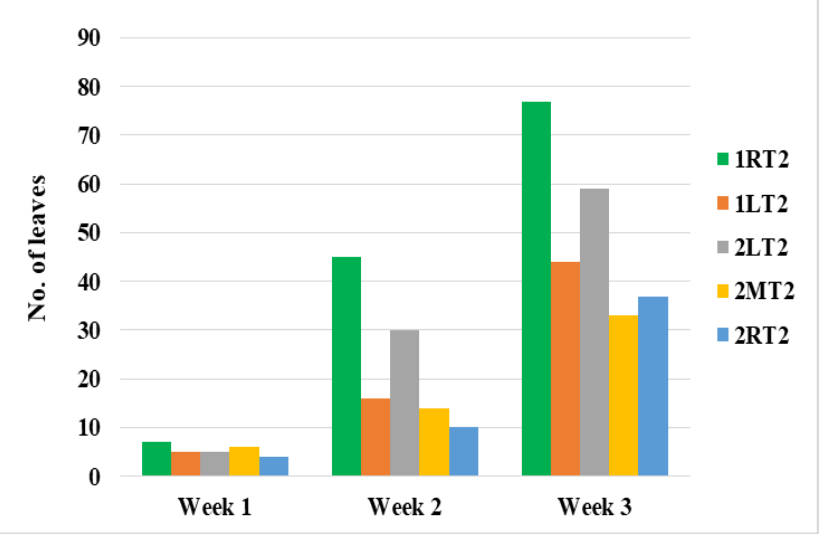

Fig. 11. Variation of number of leaves in T2 (tier 2) of DVFS 1 and DVFS 2.

during morning hours, the middle section in the afternoon and the right section in evening hours. This is due to the direction of solar radiation. Xu et al. (2020) stated that the careful orientation of structure could increase the interception of solar radiation on the rear side by $3.95 \%$.

The structural difference was also a major factor for differing light intensity. DVFS 1 was a platform like structure with triangular cross section where the possibility of getting more light in each tier is higher. But in case of DVFS 2, tiers were arranged one over the other and thereby, it might not be possible to get enough light compared to DVFS 1 due to the shade of tiers set over it. A similar result was observed by Touliatos et al. (2016), where a significant reduction of light intensity was observed from top to base of vertical columns within the vertical farming structures.

\section{Tier wise analysis of biometric observations Plant height}

The biometric observations were taken in the weekly interval. The height of randomly selected plants from each tier was observed for three weeks. The maximum plant height observed at the end of $3^{\text {rd }}$ week was on tier T1 on the right side of DVFS $1(74 \mathrm{~cm})$. A minimum plant height of $18 \mathrm{~cm}$ was found at tier T2 on the middle section of DVFS 2 . The tier wise observation made on the left and right-hand side of DVFS 1 and left, middle and right sections of DVFS 2 were taken and plotted in a graph as shown in Fig. 7-9. The growth of plants was more in DVFS 1 than in DVFS 2.

Considering the $\mathrm{T} 1$ at the end of $3^{\text {rd }}$ week, the maximum plant height of $74 \mathrm{~cm}$ was at the right side of DVFS 1. Minimum plant height was found at the right section of DVFS 2 and is about $45 \mathrm{~cm}$ (Fig. 7). At tier T2, a maximum plant height of $65 \mathrm{~cm}$ and minimum plant height of $18 \mathrm{~cm}$ were found at the right side of DVFS 1 and the middle section of DVFS 2, respectively (Fig. 8). Similarly, at tier T3, maximum plant height of

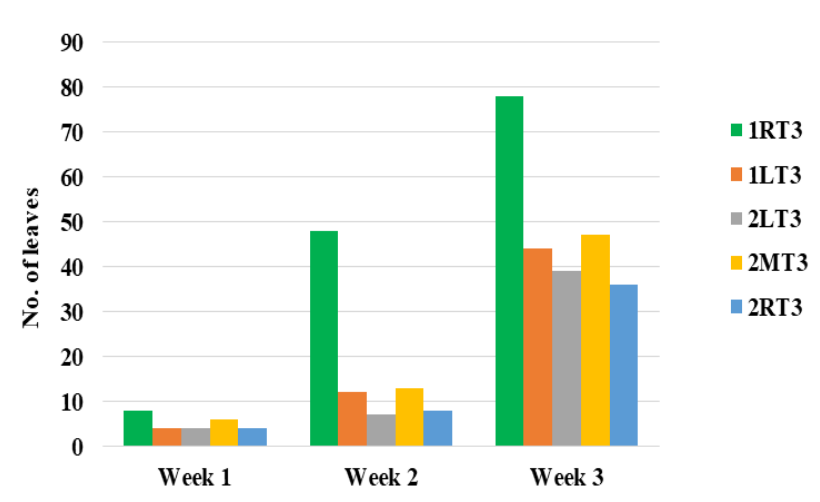

Fig. 12. Variation of plant height in T3 (tier 3) of DVFS 1 and DVFS 2.

$65 \mathrm{~cm}$ and minimum plant height of $18 \mathrm{~cm}$ were found at the right side of DVFS 1 and middle section of DVFS 2, respectively (Fig.9).

From the graphs, it is clear that plant height was observed to be maximum in the right side tier T1 followed by right side tier T3 in DVFS 1 . This was due to the variations observed in light intensity. Correlation between plant height and intensity was analysed using IBM SPSS statistics 25 software, which showed that correlation (positive correlation) was significant at 0.01 significant level with Pearson correlation coefficient of 0.935 . The result is in good agreement with the Rezazadeh et al. (2018), which reported that plant height increases at a higher intensity. Rezazadeh et al. (2018) found that higher light intensity in control and $45 \%$ shade plus long day (LD) treatments resulted in increased plant height. The positive correlation between light intensity and height of Cardinal flower (Sinningia cardinalis) was also reported previously by Kim et al. (2015).

\section{Number of leaves}

The number of leaves is also an important biometric observation usually used to analyse the crops' growth performance. At the end of 3rd week after planting, the maximum number of leaves was found in the right side of DVFS 1 and it was 87 in number. The minimum number of leaves was found in the middle section of DVFS 2, which was 33. Considering the tier T1, the maximum number of leaves was obtained at the right side of DVFS 1 and minimum was obtained the right section of DVFS 2 and was found to be 87 and 34 respectively (Fig. 10). At T2, 77 and 33 were the maximum and a minimum number of leaves obtained from the right side of DVFS 1 and middle section of DVFS 2, respectively (Fig. 11). For tier T3, the maximum and the minimum number of leaves was 78 and 36 and was found at the right side of DVFS 1 and right section of DVFS 2 (Fig. 12). 
From Fig. 9-12, it is clear that the number of leaves was observed to be maximum in DVFS 1 than DVFS 2. This also can be correlated with the light intensity as maximum light intensity was observed in these tiers. Correlation between the number of leaves and intensity was analysed using IBM SPSS statistics 25 software, which showed that correlation was significant at 0.01 significant level with Pearson correlation coefficient of 0.86 . Many studies depicted that light intensity has significant positive correlation with number of leaves and other growth parameters as it promotes growth rate (Rezai et al., 2018; Rezazadeh et al., 2018). Kang et al. (2013) observed that plants grown under treatments of high light intensity of $290 \mu \mathrm{mol} \cdot \mathrm{m}^{-2} \cdot \mathrm{s}^{-1}$ showed greater results in growth as compared to the other treatments.

\section{Yield of crop}

The harvesting was done at the end of $3^{\text {rd }}$ week. The maximum yield was obtained from DVFS 1 (61\%) than DVFS 2 (39\%). It is mainly due to the differences in the obtained light intensity. Correlation of yield data with light intensity revealed that correlation was significant at 0.01 significant level with Pearson correlation coefficient of 0.902 . This result is very much agreed with Rezazadeh et al. (2018), where he has observed a positive correlation between light intensity and biometric parameters. Similarly, Rezai et al. (2018) also found that photosynthetic rate and stomatal conductance showed a strong positive correlation with light intensity. Touliatos et al. (2016) observed a $43 \%$ reduction in crop yield in the vertical farming structures, where tiers are arranged one over the other.

\section{Conclusion}

In the present study, the climatic parameters (temperature and light intensity) and biometric observations (plant height, number of leaves, yield) were analysed to compare and evaluate the performances of two vertical farming structures, DVFS 1 and DVFS 2. The analysis of trials revealed that DVFS 1 showed better performance in every aspect compared to the DVFS 2. The biometric observations like plant height and number of leaves were more in T1 at right side and followed by T3 at the right side of DVFS 1 . The plant characteristics such as plant height, number of leaves and yield showed a significant positive correlation with the light intensity. This is the reason for more growth was observed on the right side of DVFS 1 . The maximum yield was obtained from DVFS $1(58 \%)$ than DVFS $2(42 \%)$. The analysis of trials revealed that DVFS 1 shows better performance in every aspect compared to DVFS 2. The yield data and growth performances made the results more reliable. The study recommended using the platform like structure with a triangular cross-section as it was advantageous than the structure with tiers one over the other with PVC splits. The provision for assembling and dismantling the parts of the structure, made these systems more attractive as they can move to any required areas. It is recommended for urban farming as a substitute for traditional farming practices. The designed structures can also be used in problematic soils like drought, salinity and soil with toxicity problems. In such conditions, the structure can be placed even in the field itself. The orientation of these structures can be changed according to the climatic parameters or according to our convenience.

\section{ACKNOWLEDGEMENTS}

This research was supported by Kelappaji College of Agricultural Engineering and Technology, Tavanur. The author would like to thank Tamil Nadu Agricultural University, Coimbatore, for the support towards publication, the Journal's reviewers for providing helpful comments, and the staff for careful and professional work.

\section{Conflict of interest}

The authors declare that they have no conflict of interest.

\section{REFERENCES}

1. Al-Kodmany, K. \& Ali, M.M. (2013). The Future of the City: Tall Buildings and Urban Design, WIT Press, Southampton, UK.

2. Al-Kodmany, K. (2018). The vertical farm: A review of developments and implications for the vertical city. Buildings, 8 (2),24, https://doi.org/10.3390/buildings8020024

3. Al-Kodmany, K. (2018a). The Vertical City: A Sustainable Development Model, WIT Press, Southampton, UK.

4. Despommier, D. (2010). The Vertical Farm: Feeding the World in the 21st Century, Thomas Dunne Books, New York, NY, USA

5. Franzese, M. \& Luliano, A. (2018). Correlation analysis. Encyclopedia of Bioinformatics and Computational Biology: $A B C$ of Bioinformatics (Eds.: S, Ranganathan,, K. Nakai and C. Schonbach ). Elsevier Inc., pp 706-721.

6. Healy, R.G. \& Rosenberg, J.S. (2013). Land Use and the States; Routledge: New York, NY, USA.

7. Kang, J.H., KrishnaKumar, S., Atulba, S.L.S., Jeong, B.R. \& Hwang, S.J. (2013). Light intensity and photoperiod influence the growth and development of hydroponically grown leaf lettuce in a closed-type plant factory system. Horticulture Environment and Biotechnology, 54(6), 501509. https,//doi.org/10.1007/s13580-013-0109-8

8. Kim, J.H., Lee, A.K., Roh, M.S. \& Suh, J.K. (2015). The effect of irradiance and temperature on the growth and flowering of Sinningia cardinalis. Sci. Hortic., 194, 147153. https://doi.org/10.1016/j.scienta.2015.07.040

9. Lamnatou, C. \& Chemisana, D. (2013). Solar radiation manipulations and their role in greenhouse claddings: Fluorescent solar concentrators, photoselective and other 
materials. Renewable and Sustainable Energy Reviews, 27,175-190. https://doi.org/10.1016/j.rser.2013.06.052

10. Marcelis, L.F.M., Broekhuijsen, A.G.M., Meinen, E., Nijs, E. M.F.M. \& Raaphorst, M.G.M. (2006). Quantification of the growth response to light quantity of greenhouse grown crops. Acta Horticulturae, 711(9), 97-103. https:// doi.org/10.17660/ActaHortic.2006.711.9

11. Michel, M.A., Tutikian, B.F., Ortolan, V., Oliveira, M.L.S., Sampaio, C.H., Gómez P.L. \& Silva, L.F.O. (2019). Fire resistance performance of concrete-PVC panels with polyvinyl chloride (PVC) stay in place (SIP) formwork. Journal of Materials Research and Technology, 8(5), 4094-4107. https://doi.org/10.1016/j.jmrt.2019.07.018

12. Omrani, S., Garcia-Hansen, V., Capra, B.R. \& Drogemuller, R. (2017). On the effect of provision of balconies on natural ventilation and thermal comfort in high-rise residential buildings. Building and Environment, 123, 504-516. https://doi.org/10.1016/j.buildenv.2017.07.016

13. Postel, S., Polak, P., Gonzales, F. \& Keller, J. (2001). Drip irrigation for small farmers - A new initiative to alleviate hunger and poverty. Water Int., 26 (1), 3-13. https:// doi.org/10.1080/02508060108686882

14. Pradeepkumar, T., Suma, B., Jyothibhaskar \& Satheesan, K.N. (2018). Management of Horticultural Crops, part 2., New India Publishing Agency, Pitam Pura, New Delhi.

15. Rani, R., Sehrawat, S.K. \& Pal, M. (2018). Rooting and acclimatization of tissue cultured raised seedling of banana cv. grand naine. Int. J. Sci. Nature, 9(2), 206-208.

16. Rezai, S., Etemadi, N., Nikbakht, A., Yousefi, M. and Majidi, M.M. (2018). Effect of light intensity on leaf morphology, photosynthetic capacity, and chlorophyll content in sage (Salvia officinalis L.). Horticultural Science and Technology, 36(1), 46-57. https://doi.org/10.12972/kjhst.2 0180006

17. Rezazadeh, A., Harkess, R.L. \& Telmadarrehei, T. (2018). The effect of light intensity and temperature on flowering and morphology of potted red Firespike. Horticulturae, 4 (4),1-7. https,//doi.org/10.3390/horticulturae404 0036

18. Sethi, V.P. (2009). On the selection of shape and orientation of a greenhouse for composite climates. International Journal of Sustainable Energy, 28(1-3), 45-58. https:// doi.org/10.1080/14786450802452621

19. The United Nations (2017). World Population Prospects: The 2017 Revision, United Nations: New York, NY, USA.

20. Thomaier, S., Specht, K., Henckel, D., Dierich, A., Siebert, R., Freisinger, U.B. \& Sawicka, M. (2015). Farming in and on urban buildings: Present practice and specific novelties of zero-acreage Farming (ZFarming). Renew. Agric. Food Syst., 30,43-54. https://doi.org/10.1017/S1742170 5140 00143

21. Touliatos, D., Dodd, I.C. \& Mcainsh, M. (2016). Vertical farming increases lettuce yield per unit area compared to conventional horizontal hydroponics. Food and Energy Security, 5(3), 184-191. https://doi.org/10.1002/fes3.83

22. Valley, W. \& Wittman, H. (2018). Beyond Feeding the City: The Multifunctionality of Urban Farming in Vancouver, BC. City, Culture and Society.

23. Vazquez, N., Pardo, A., Suso, M.L. and Quemada, M. (2006). Drainage and nitrate leaching under processing tomato growth with drip irrigation and plastic mulching. Agric. Ecosyst. Environ., 112 (4), 313-323. https:// doi.org/10.1016/j.agee.2005.07.009

24. Wang, Y., Li, S., Qin, S., Guo, H., Yang, D. \& Lam, H. M. (2020). How can drip irrigation save water and reduce evapotranspiration compared to border irrigation in arid regions in northwest China. Agricultural Water Management, 239. https://doi.org/10.1016/j.agwa t.2020.106256

25. Xu, D., Li, Y., Zhang, Y., Xu, H., Li, T. \& Liu, X. (2020). Effects of orientation and structure on solar radiation interception in Chinese solar greenhouse. PLOS ONE, 15(11), 1-17. https://doi.org/10.1371/journal.pone.0242002 